\title{
Review of the genus Tricerophora Janse, 1958 (Lepidoptera, Gelechiidae) with description of six new species
}

\author{
Oleksiy V. Bidzilya ${ }^{1}$, Wolfram $\mathrm{Mey}^{2}$ \\ 1 Institute for Evolutionary Ecology of the National Academy of Sciences of Ukraine, 37 Academician Lebedev str., 03143, Kiev, Ukraine \\ 2 Museum für Naturkunde, Leibniz Institute at Humboldt Universität, Invalidenstrasse 43, D-10115, Berlin, Germany
}

http://zoobank.org/4FE56A19-4D03-4C35-B4E5-CB1E7469B4CC

Corresponding author: Oleksiy V. Bidzilya (olexbid@gmail.com)

Received 12 April 2018

Accepted 4 June 2018

Published 12 June 2018

Academic editor:

Dominique Zimmermann

\section{Key Words}

\section{Gelechiinae}

Leucophylla

new species

new synonym

Afrotropical region

Namibia

South Africa

Kenya

Palaearctic region

Iran

\begin{abstract}
An improved diagnosis of the genus Tricerophora is provided, and its position within Gelechiidae is briefly discussed. A new generic synonym is established: Leucophylla Janse, 1960, syn. n. of Tricerophora Janse, 1958. Six new species are described: T. pundamilia sp. n. (RSA), T. rukinga sp. n. (Kenya), T. nigrinervis sp. n. (RSA, Namibia), T. brumale sp. n. (Namibia), T. acutivalva sp. n. (Iran), T. minimorum sp. n. (Namibia). The following new combinations are proposed: Tricerophora nigribasis (Janse, 1960), comb. n., Tricerophora objecta (Meyrick, 1921), comb. n. A key to the species is given based on external characters and the genitalia of both sexes. Adults and genitalia of all species are illustrated.
\end{abstract}

\section{Introduction}

Since their descriptions, the gelechiid genera Tricerophora Janse, 1958 and Leucophylla Janse, 1960, were considered as monotypic taxa restricted to southern Africa (Namibia, RSA, Mozambique, Zimbabwe). Recent field work in southern (Mey 2011) and eastern Africa (D.J.L. Agassiz in 2010 and 2012) yielded new material of these groups, which turned out to be more species-rich than previously thought. The examination of this fresh material resulted in the discovery of six additional species collected in RSA, Namibia, Kenya and South Iran. The study of the type species of Tricerophora and Leucophylla revealed a high similarity that does not justify the recognition of two different genera and led us to accept only a single genus with Tricerophora as the oldest available name. We also found that Telphusa objecta Meyrick, 1921 belongs to Tricerophora too. With the discovery of additional new species we are now able to provide an improved and more detailed diagnosis of the genus Tricerophora. On this basis we provide some suggestions about the phylogenetic relationship of the genus and its possible sister group, and discuss briefly the position of Tricerophora within the family Gelechiidae. 


\section{Material and methods}

The present paper is based on material from the following collections:

Museum für Naturkunde, Berlin, Germany (MfN), Ditsong National Museum of Natural History of South Africa (formerly Transvaal Museum), Pretoria, South Africa (TMSA), Staatliches Museum für Naturkunde Karlsruhe, Germany (SMNK), Landesmuseum für Kärnten, Klagenfurt, Austria (LMK), Muséum d'histoire Naturelle, Geneva, Switzerland (MHNG) and the research collection of David Agassiz, London, UK (DA) (later transferred to BMNH).

The genitalia slides were prepared according to the "unrolling technique" described in Pitkin (1986) and Huemer (1988). The genitalia were embedded in Euparal. Chlorazol Black and mercurochrome were used for staining. Photographic documentation of the imago was done with Olympus E-410 digital camera attached to microscope Olympus SZX12. Slide-mounted genitalia were photographed with a Canon EOS 600D digital camera mounted on Olympus U-CTR30-2 combined with Carl Zeiss microscope. Holotype label data are quoted verbatim: quotation marks (") signify data on a single label, the end of a line of print is indicated by comma (,) and a straight slash (|) separates labels. Supplementary or qualifying information is provided in square parentheses.

The descriptive terminology of genitalia structures generally follows Huemer and Karsholt (1999) and Kristensen (2003).

\section{Taxonomic account}

\section{Check-list of the genus Tricerophora}

T. commaculata (Meyrick, 1921)

T. nigribasis (Janse, 1960), comb. $\mathrm{n}$.

T. sp. A

T. pundamilia sp. $\mathrm{n}$.

T. rukinga $\mathrm{sp}$. $\mathrm{n}$.

T. objecta (Meyrick, 1921), comb. n.

T. brumale sp. $\mathrm{n}$.

T. nigrinervis $\mathrm{sp} . \mathrm{n}$.

T. acutivalva $\mathrm{sp} . \mathrm{n}$.

T. minimorum sp. $\mathrm{n}$.

\section{Tricerophora Janse, 1958}

Moths of South Africa 6 (1): 64

Type species: Telphusa commaculata Meyrick, 1921

Leucophylla Janse, 1960, syn. n.

Moths of South Africa 6 (2): 202

Type species: Leucophylla nigribasis Janse, 1960

Diagnosis. Most of Tricerophora species are defined by white forewings with black pattern along longitudinal axis without transverse fasciae and dark spots in cell and fold that are common in many other genera of Gelechiidae. Thiotrichinae genus Polyhymno Chamners, 1874 has somewhat similar wing pattern to Tricerophora, but species of Polyhymno are usually smaller in size and pattern along longitudinal axis is brown rather than black in Tricerophora.

The tegumen with a strongly sclerotized posterior belt and lateral processes as well as very narrow, long uncus are considered to be presumed autapomorphies of Tricerophora.

The female genitalia are characterized by laterally sclerotized segment VIII, well developed antrum, entirely sclerotized ductus bursae in most species, and usually long, serrated arms of the signum.

Species of Tricerophora shares the male abdominal segment VIII separated into free tergum and sternum and the presence of a sub-rhomboid or hexagonal signum in females with members of the subfamily Gelechiinae (Huemer \& Karsholt 1998: 19). The diagnosis of Gelechiinae was recently improved and clarified on the basis of DNA sequence data for one mitochondrial gene and seven nuclear genes (Karsholt et al 2013). It confirmed the subdivision of subfamily into three tribes - Litini, Gelechiini and Gnorimoschemini based on above mentioned construction of male abdominal segment VIII that is considered as the only synapomorphy of Gelechiinae. Tricerophora along with most of related genera has not been considered in the recent classification of Gelechiidae (Karsholt et al. 2013). However, we suggest, that within this subfamily the male genitalia of Tricerophora display some similarity to those of the genus Trychnopalpa Janse, 1958 by the shape of the uncus (Janse 1960: 203) and the posteriorely modified tegumen. The latter genus can be separated from Tricerophora by a quite different gnathos and the presence of well developed, paired process on the posterior margin of the vinculum. Both genera differ additionally in the shape of the phallus, which is shorter and devoid of cornuti in the vesica in Trychnopalpa. The genus Agnippe Chambers, 1872 shares with species of Tricerophora a long, flat gnathos, a long and narrow uncus, cornuti in the vesica but differs by the structure of the gnathos which is separated on dorsal and ventral parts, by the absence of posterior belt-shaped sclerite of tegumen and by the presence of a sclerotized plate in the vesica (Bidzilya and Li 2010). The evenly sclerotized and unmodified sternum VIII and well developed antrum in the female genitalia indicate an affinity of Tricerophora with some genera of the tribe Gelechiini like Mirificarma Gozmány, 1955, Chionodes Hübner, [1825] and Aroga Busck, 1914. The female genitalia of Agnippe are similar to those of Tricerophora too, except for the corpus bursae with long accessory and spines inside that is characteristic for Agnippe. However, a somewhat similar but much shorter accessory is observed in T. nigrinervis which also points to a close relationship of both genera.

The tribal assignment of Tricerophora is rather questionable and difficult to determine. The tendency of form- 
ing an accessory bursae in the female genitalia is observed both in genera of Litini (Parastenolechia Kanazwa, 1985; Parachronistis Meyrick, 1925) and Gelechiini (Agnippe). However, the long antrum, the well developed culcitula and the valva, divided into long cucullus and short sacculus are characteristic for Gelechiini (Ponomarenko 2005; Huemer and Karsholt 2010). So, we tentatively place Tricerophora into Gelechiini, until the systematic position of this genus will be clarified in future by using molecular methods.

The genus Leucophylla Janse, 1960 was established as monotypic for L. nigribasis Janse, 1960. Janse (1960) assumed a relationship of Leucophyla to Trychnopalpa by sharing the same form of the uncus in the male genitalia and a similar signum in the female genitalia. He mentioned that both genera differ in the scale cover of the labial palpi, wing venation and the shape of the phallus. The male genitalia of Leucophylla match well of those of T. commaculata, the type-species of the genus Tricerophora. Also, the female genitalia fit to T. commaculata except for the indistinctly formed ostium. However, the examination of the new species of Tricerophora shows that this character is rather variable: the ostium may be well developed or indistinct in species whose male genitalia undoubtedly match that of Tricerophora. Hence, the following synonymy is proposed here: Leucophylla Janse, 1960, syn. n. of Tricerophora Janse, 1958.

Description. Adult. Head smoothly scaled, ocelli absent, light, usually off-white or grey, labial palpus strongly up-curved, far protruding over the head, segment 2 with tuft of long scales at base, underside with short brush of scales; segment 3 about as long as segment 2, narrow, pointed. Scape without pecten, male flagellomeres finely ciliated underside.

Thorax white, often mottled with grey or brown, yellowish-white in T. minimorum; tegulae the same color as thorax; forewing elongated, moderately narrow, wingspan 7.0-18.0 mm, ground color white to light grey with black pattern along veins, or forewing grey with basal touch at base of costal margin and diffuse black spots under costa (T. nigribasis); in T. minimorum the forewing is uniformly yellowish-white; hindwing grey, narrow with small subapical excavation, cilia grey.

Abdomen: Male tergum VIII longer than broad, tongue-shaped or triangular, with long haired coremata at base, sternum VIII broader than long, posterior margin broadly rounded. Female segment VII 1.5 times as long as rest of abdominal segments, trapezoidal, weakly narrowed posteriorly.
Male genitalia. Posterior margin of tegumen strongly sclerotized forming a belt-shaped sclerite terminated laterally in narrow short processes (reduced in T. rukinga), medially with a stout, long, narrow uncus with a pointed tip; gnathos flat, weakly sclerotized, elongated; culcitula well developed, membranous; tegumen sub-rectangular, about twice as long as broad, anterior margin with deep, triangular emargination; valva elongated, narrow or moderately broad, straight, of even width or curved inwards at $1 / 3$, densely covered with hairs after halfway; sacculus short and slender in most species, merged with valva in $T$. acutivalva or stout, broad, with inwardly curved tip in $T$. rukinga, displaced medially in $T$. commaculata, posterior margin with weakly sclerotized, medial lobe; saccus long and narrow, sub-triangular in T. rukinga and T. acutival$v a$; phallus tubular, weakly swollen on base (except for $T$. rukinga), with lateral sclerotized filaments, vesica with one or two (T. nigrinervis) cornuti.

Female genitalia. Segment VIII slightly longer than broad, weakly sclerotized; sternum VIII simple, evenly sclerotized, usually more or less covered with microtrichia, with narrow lateral sclerites extending from the base of apophysis anterioris to the posterior margin of sternum, anterior margin strongly sclerotized, projecting medially into well developed tubular or funnel-shaped antrum; ostium rounded, ovate or funnel-shaped, strongly edged with several transverse rings, placed near posterior margin of sternite VIII, or indistinct; apophysis anterioris narrow, straight, about as long as length of segment VIII or longer, apophysis posterioris three-five times as long as apophysis anterioris; ductus bursae varies considerably in length and width, with long sclerotized portion that is connected with antrum or separated ( $T$. nigribasis), sometimes entirely sclerotized (T. rukinga), with numerous short teeth (T. sp. A) or with serrated folds projecting into the corpus bursae (T. nigrinervis); corpus bursae rounded or sub-ovate, with posterolateral, partially sclerotized accessory in T. nigrinervis; signum a sub-hexagonal plate with short lateral arms, deep medial ridge and long usually serrated laterally anterior and posterior arms.

Biology. Host plant unknown. Adults have been collected from August to December, in February-March and in June in southern Africa up to 1740 m elevation (Brandberg Massive in Namibia), in November in Kenya, in August in DR Congo and in early June in South Iran.

Distribution. Afrotropical Region (RSA, Namibia, Mozambique, Zimbabwe, Kenya, DR Congo) and Palaearctic Region (South Iran).

\section{Key to adults based on external characters}

(Note: T. commaculata, T. pundamilia sp. n. and T. rukinga sp. n. can hardly be distinguished from each other without examination of genitalia) 
$3 \quad$ Wingspan 13.2-18.0 mm, predominantly black

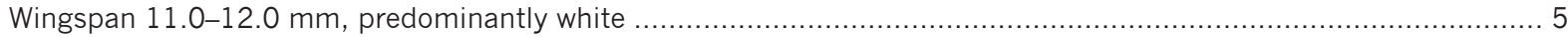

4. Forewing with paired white triangular spot in the middle of the costal and dorsal margin........... T. objecta

- $\quad$ Forewing without paired white triangular spot in the middle of the costal and dorsal margin T. commaculta, $T$. pundamilia sp. n., T. rukinga sp. $\mathrm{n}$.

5 Head and thorax snow-white, forewing with three broad black-lined veins T. nigrinervis sp. $\mathrm{n}$. Head and thorax mottled with brown, forewing less contrasting.

\section{Key to males based on genitalia}

(Note: T. sp. A. is not included in the key due to its unclear taxonomic state; the male of T. pundamilia sp. n. is unknown)

Valva inwardly broadened on base and curved inwardly before middle...

Sacculus broader than valva, with inwardly curved tip, uncus longer than tegumen, gnathos trifid apically .. T. rukinga sp. $\mathrm{n}$. Sacculus narrower than valva, straight, uncus shorter than tegumen, gnathos rounded or truncate apically.............. 4 Posteromedial lobe of vinculum about half length of valva, phallus with two cornuti ...................... T. nigrinervis sp. $\mathrm{n}$. Posteromedial lobe of vinculum shorter than half length of valva, phallus with single cornutus.............................. 5 Gnathos of even width..... T. nigribasis Gnathos broadened apically .... Gnathos sub-triangular, truncated posteriorly

\section{Key to the females based on genitalia}

1 Sternum VIII extremely anteriorly prolonged with a large, medial membranous window T. objecta

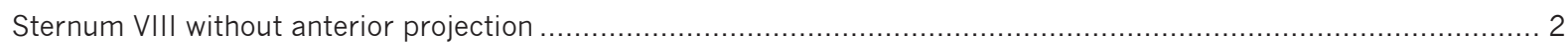

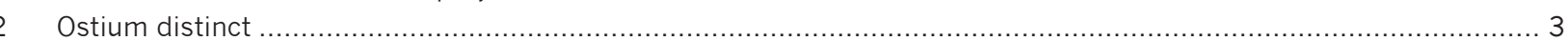

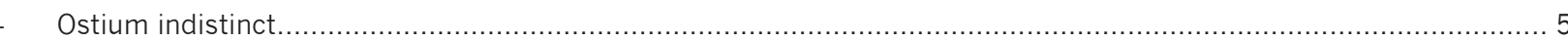

3 Ostium funnel-shaped, ductus bursae membranous, as long as antrum .................................... T. commaculata

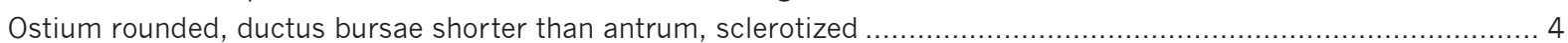

4 Ostium sub-ovate, with two transverse sclerotized belts, ductus bursae with teeth ......................... T. pundamilia sp. n. Ostium bursae rounded, with one transverse sclerotized belt, ductus bursae without teeth................... T. rukinga sp. $\mathrm{n}$.

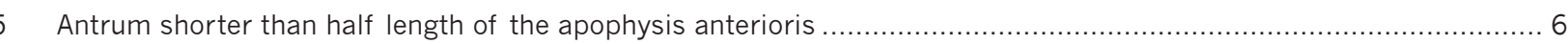

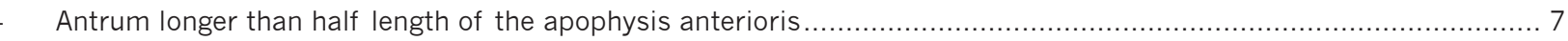

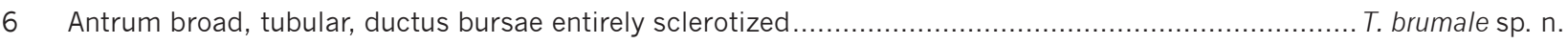
Antrum narrow, funnel-shaped, ductus bursa sclerotized in proximal half .............................. T. minimorum sp. n.

7 Ductus bursae with several strongly serrated folds projecting into the corpus bursae ......................... . nigrinervis sp. $\mathrm{n}$.

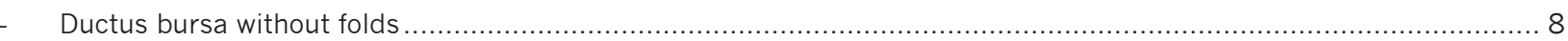

8 Ductus bursae sclerotized in medial portion, anterior arm of signum truncate .....................................

- $\quad$ Ductus bursae sclerotized in distal half, anterior arm of signum narrowed apically ....................... T. acutivalva sp. n.

\section{Review of species}

\section{Tricerophora commaculata (Meyrick, 1921)}

Telphusa commuculata Meyrick, 1921 - Annals of the Transvaal Museum 8 (2): 69

Type material examined. Holotype of T. commaculata, : : [Mozambique] "Magude, 11.1910, C.J. Swierstra" | "Telphusa commaculata Meyr., Type Mo. 2517." | “g. 5544”| "994” (TMSA). Paratypes: 2 ふ, Inyack Isl., ix.1910 (Breijer) (gen. slide 5282, 8617) (TMSA).
Other material examined. 1 ex. (abdomen missing), [Mozambique] Lour. Marques, xi.3.21, P.E.A. (Hardenberg); 1 ô, 1 ex. (abdomen missing), [South Africa], Pretoria N., ix. 1949 (G. v. Son) (gen. slide 8408); 1 9, Pretoria N., x.1948 (G. van Son) (gen. slide 8406); 2 Jे, Zoutpan, Pta, 4-10. ii.1929 (G.v.Son) (gen. slide 5152; 606/14, O. Bidzilya); 1 ô, Lower Sabi, 26.iii. 1952 (Janse \& Vari); 1 ex. (abdomen missing), Lower Sabi, 26.iii.1962 (Janse \& Vari) (all TMSA); 1 స̃, Zimbabwe, Bulawayo, Matopo Nat. Park, 28-30.xi.1993 (Mey \& Ebert) (gen. slide 322/07, O. Bidzilya) (MfN).

Diagnosis. The species is defined by black forewings with white area along dorsal margin and diffuse white 
spots on $1 / 3$ and $2 / 3$ on costal margin. Externally is nearly indistinguishable from $T$. rukinga $\mathrm{sp} . \mathrm{n}$. and T. pundamilia sp. $\mathrm{n}$. The valva, broadened medially on base, wrinkled and curved inwardly before middle, and the medially displaced sacculus are characteristic for the male genitalia. The female genitalia are distinct by the tubular antrum sub-equal in length with sternum VIII and the apophysis anterioris, together with the funnel-shaped ostium and long arms of the signum.

Description. Adult (Figs 1-4): Wingspan 15.0-18.0 $\mathrm{mm}$. Head, thorax and tegula white to light grey; segment 2 of labial palpus with short tufts of scales at base, underside with brush of scales, outer surface black at base, three brown rings from middle to apex of segment, inner surface off-white; segment 3 narrow, pointed, light grey irregularly mottled with black; forewing narrow, prolonged, ground colour grey-whitish, densely mottled with brown and black-tipped scales, costal margin with black touch at base and in middle, broad black medial fascia from base to apex, fringe grey black-tipped; hindwing narrow, grey, apex short, weakly pointed.

Male genitalia (Fig. 21): Posterolateral processes of tegumen short, pointed; uncus long, evenly curved; gnathos half the length of uncus, gradually broadened towards rounded top; tegumen a little more than twice as long as broad; valva moderately broad, weakly extending beyond the top of uncus, distinctly curved inwards and wrinkled at $1 / 3$, inwardly broadened on base, hairy after half length, apex pointed; sacculus displaced medially, about $1 / 4$ length of valva, with outwardly curved tip; vinculum three times as broad as long and length $1 / 4$ of valva, posteromedial lobe narrow, pointed apically, about 1/4-1/5 length of valva; saccus broad,weakly narrowed towards rounded apex; phallus weakly swollen on base, distal portion weakly sclerotized, cornutus weakly curved, finely serrated.

Female genitalia (Fig. 29): Sternum VIII 1.5 times as long as broad, lateral sclerites broadened in basal half; ostium funnel-shaped, strongly edged, weakly wrinkled; apophysis anterioris about as long as a length of segment VIII; antrum sub-equal in length in apophysis anterioris, tubular; ductus bursae as long as antrum, weakly broadened towards corpus bursae, with short colliculum; corpus bursae sub-ovate; signum with long serrated arms, the anterior one slightly longer than the posterior one, placed in lateral broadening of the corpus bursae.

Distribution. RSA, Mozambique, Zimbabwe.

Biology. Adults have been collected from September to November and in February-March.

Notes. T. commaculata was described on the basis of one female holotype collected in Magude (Mozambique) and two male paratypes from Inyack Island (Mozambique). Additional specimens associated by Janse with T. commaculata are from Lourenço Marques (Mozambique), Pretoria, Zoutpan and Kruger National Park (RSA). The holotype matches externally both to paratypes and other specimens except for the head and labial palpi that are white in holotype rather than greyish-white.
However, the female genitalia of the holotype (gen. slide 5544) do not match the female from Pretoria (gen. slide 8406) that is figured in the original description (Janse 1960, Pl. $57 \mathrm{~g}, \mathrm{~h}$ ). The males including ones from Pretoria and Zoutpan, are similar externally to the female from Pretoria and identical in the genitalia to each other. It is remains unclear if these males are conspecific with the female holotype from Magude or with the female from Pretoria. We provisionally follow Janse and consider the males being $T$. commaculata until additional material becomes available.

\section{Tricerophora nigribasis (Janse, 1960), comb. n.}

Leucophylla nigribasis Janse, 1960 - Moths of South Africa 6 (2): 203

Tricerophora sp. 1 - Bidzilya 2007: 99, figs 32, 36; pl. 7, fig. 2

Type material examined. Holotype of L. nigribasis, $\widehat{\jmath}$ : [RSA] "Pentonville, 60 m, N.W Vaalwater, 27.ix.1953, Harvey \& Rorke" | "Leucophylla nigribasis J., ô, HOLOTYPE No: 3729.” | "g. 8455” (TMSA). Paratypes: 1 q, same data as for holotype (gen. slide 8456); $1 \hat{\jmath}$, same data as for holotype (gen. slide 599/14, O. Bidzilya); 1 ㅇ, [Namibia] Abachaus, S.W.A., Oct. 43 (Hobohm); 1 , Abachaus, S.W.A., xi' 45 (Hobohm) (gen. slide 600/14, O. Bidzilya) (all TMSA).

Material examined. 1 ๙, 2 , [Namibia], Brandberg, Mason Shelter, 1740 m, 5, 7.iii.2002 (Mey) (gen. slide

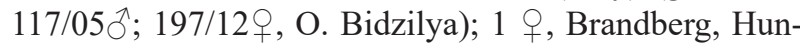
garob-valley, 17.iii.2001, $1200 \mathrm{~m}$ (gen. slide 105/05, O. Bidzilya) (all MfN).

Diagnosis. The species is easy recognized by light grey forewing with prominent black touch on base of costal margin, distinct black streak in fold and diffuse black spots under costal margin. The male genitalia are defined by parallel-sided gnathos which is sub-equal in length with uncus, in combination with short, slender saccus, slender valva and phallus with basally broadened cornutus. T. nigrinervis $\mathrm{sp}$. $\mathrm{n}$. differs from other congeners by the longer posteromedial lobe of vinculum, longer valva, sacculus and phallus. The comparatively long ductus bursae with a long medially sclerotized portion separated from antrum is diagnostic for T. nigribasis.

Description. Adult (Figs 5-6): Wingspan 14.0-18.0 $\mathrm{mm}$. Head, thorax and tegulae white, slightly mottled with brown; segment 2 of labial palpus light grey, base black, brush of raised scales underside, segment 3 slender, acute. Forewing light-grey, black-tipped scales forming indistinct touch at the base of cell, mainly concentrated in subapical area, black spot in the middle and black point in the cell corner, costal margin with obvious black touch at base, diffuse black spots in middle and in 3/4, cilia grey, black-tipped; hindwing and cilia grey.

Male genitalia (Fig. 22): Posterolateral processes of tegumen short, pointed; uncus long, evenly curved; gna- 

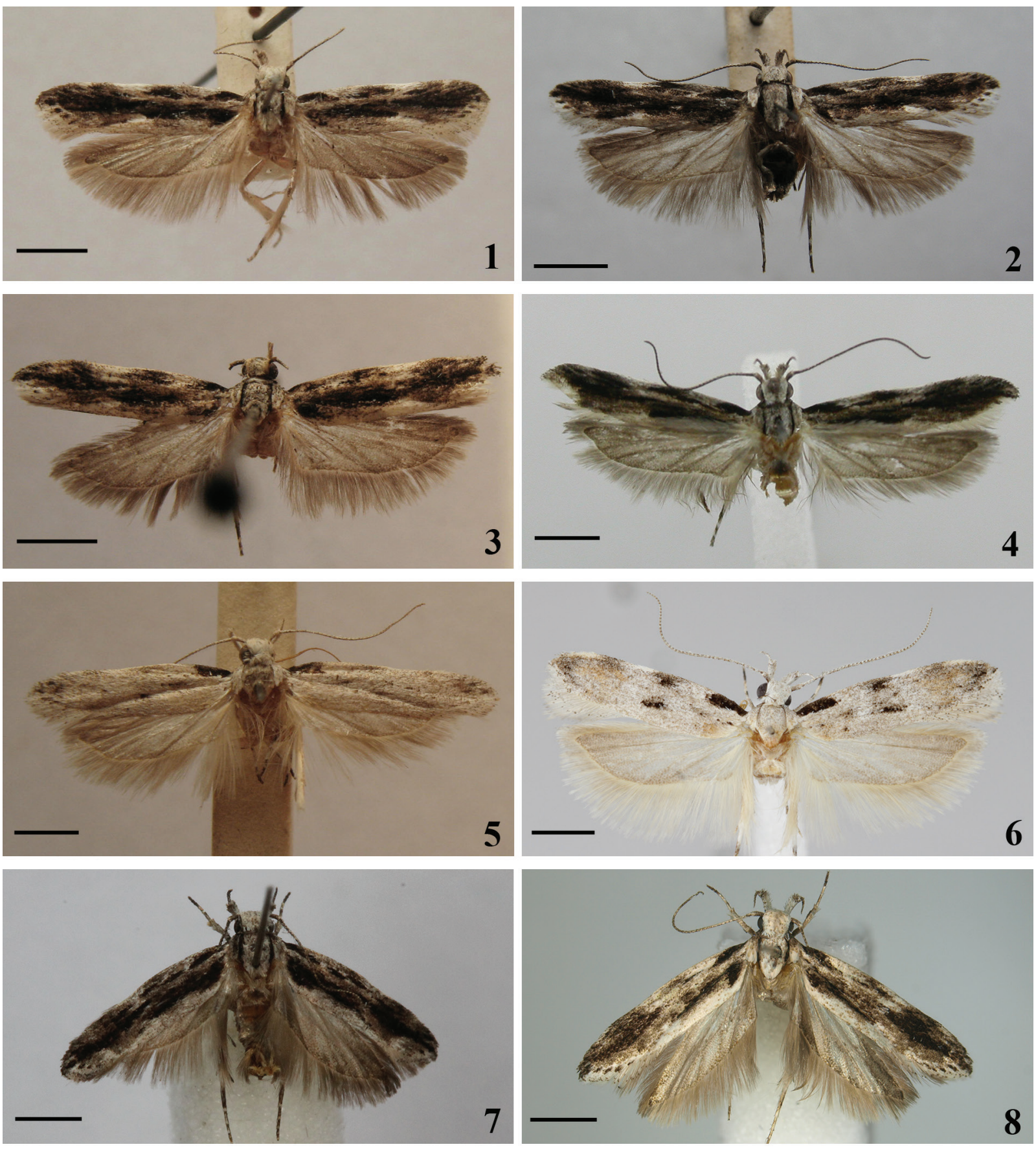

8
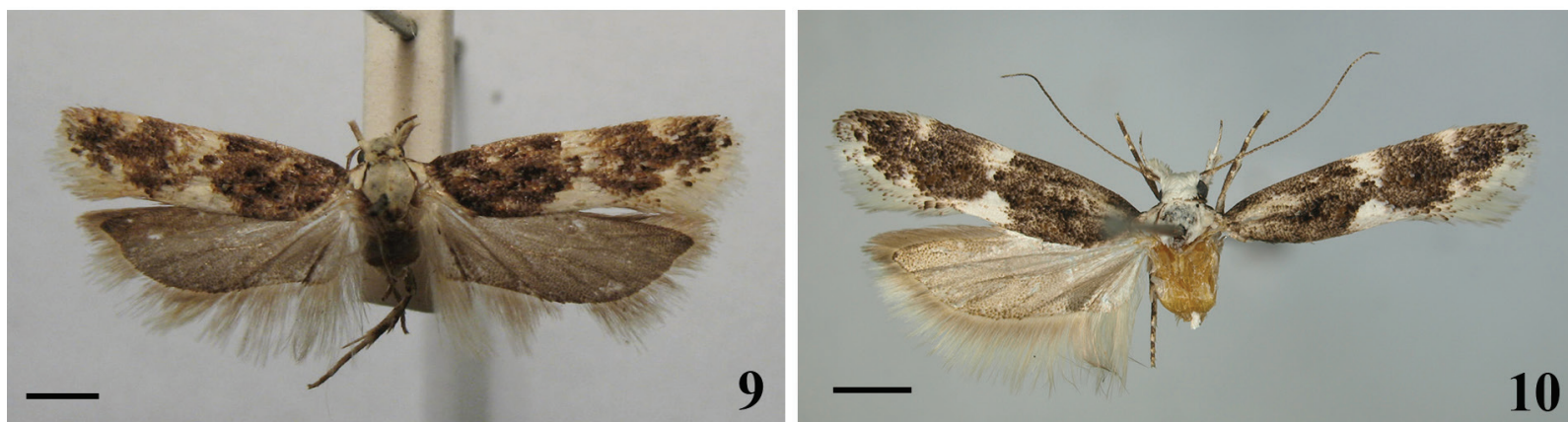

Figures 1-10. Adult of Tricerophora spp. 1-4. T. commaculata. 1. HT,, , Magude (gen. slide 5544). 2. PT, ô, Inyack Isl. (gen. slide 8617). 3. ㅇ, Pretoria (gen. slide 8406). 4. Zimbabwe, ô (gen. slide 322/07, O. Bidzilya). 5-6. T. nigribasis. 5. HT, ô, Pentonville (gen. slide 8455). 6. §, Brandberg (gen. slide 117/05, O. Bidzilya). 7-8. T. rukinga sp. n. 7. HT, §̂, Rukinga (gen. slide 324/14, O. Bidzilya (= 1542, DJLA)). 8. PT, ㅇ, Rukinga (gen. slide 325/14, O. Bidzilya (=1543, DJLA)). 9-10. T. objecta. 9. HT, q, Harare. 10. + , Kenya, Tschinkolobwe (gen. slide 103/18, O. Bidzilya). Scale bar $=2 \mathrm{~mm}$. 
thos slightly shorter than uncus, of even width, tip rounded; tegumen two times as long as broad; valva nearly straight, narrow, of even width except for weakly broadened distal $1 / 4$, rarely haired, slightly extending beyond the tip of uncus, apex pointed; sacculus about 1/6 length of valva; vinculum 1.5 times as broad as long, slightly more than two times shorter than valva, posteromedial lobe extending to about $1 / 6$ length of the valva, medially with broad triangular emargination; saccus gradually narrowed in middle; phallus weakly swollen on base, cornutus straight, broadened at base.

Female genitalia (Fig. 33): Sternum VIII slightly broader than long, weakly sclerotized, covered with microtrichia and finely wrinkled in basal $2 / 3$; ostium indistinct; apophysis anterioris as long as a length of segment VIII; antrum broad on base, then tubular, 2/3 length of apophysis anterioris; colliculum broad; ductus bursae three times as long as apophysis anterioris, narrow, weakly broadened towards corpus bursae, sclerotized in medial portion; corpus bursae egg-shaped, arms of signum of equal length, anterior one truncate, posterior one weakly narrowed apically, laterally serrated.

Distribution. RSA, Namibia.

Biology. Adults have been collected in September-November and March up to $1740 \mathrm{~m}$ elevation at the Brandberg (Namibia).

Notes. Leucophila nigribasis was described from two males (including the holotype) and one female collected in Pentonville (South Africa, Limpopo) and five females from Abachaus (Namibia). Janse (1960: 203) noted that females from Abachaus are smaller (14 $\mathrm{mm}$ instead of $18 \mathrm{~mm})$ and darker than the specimens from Pentonville. However, the female genitalia are identical indicating their conspecifity. One male and three females from the Brandberg match externally to the female paratypes from Abachaus having the forewing densely irrorated with grey and a wingspan of 14.1-15.2 mm. The male genitalia (gen. slide 117/05, O. Bidzilya) are identical with the holotype and paratype from Pentonville. However, the genitalia of two females (gen. slide 105/05; 197/12, O. Bidzilya) differ considerably (Fig. 34) from female paratypes from Pentonville and Abachaus. The females from Brandberg may represent a further, undescribed species, whose male is unknown.

\section{Tricerophora sp. A}

Material. 1 ${ }^{\lambda}$, [RSA] Wylies Poort, 3 m, North, 16.vi.1954 (Janse) (gen. slide 331/14, O. Bidzilya) (TMSA)

Notes. The male genitalia of this single specimen (Fig. 23) differ significantly from the other species of Tricerophora. However, taking into account the extreme similarity in habitus among this species (Fig. 12), T. commaculata and T. pundamilia sp. n. we can not rule out that this specimen might be the opposite sex of one of the following species (see also remarks to T. commaculata). Therefore we refrain from naming the species to avoid confusion in future.

\section{Tricerophora pundamilia sp. n.}

http://zoobank.org/B6A0D54C-A6B7-4D56-87A5-A49E295F8AB7

Type material. Holotype ${ }_{+}$, [RSA] "Punda Milia, K.N.P. Survey, 1-5.xii.1964, Vari \& Potgieter" | "gen. slide 61/15, O. Bidzilya” (TMSA)

Diagnosis. The new species is characterized externally by predominately black forewing with white pattern along dorsal margin and white diffuse spots on $1 / 3$ and $2 / 3$ of costal margin. T. commaculata is very similar, but differs in the white head without black irroration and the dorsal margin of the forewing mottled with black. A subovate ostium with two transverse sclerotized belts and sclerotized anterior margin in combination with very short ductus bursae that bears teeth are characteristic for the female genitalia.

Description. Adult (Fig. 11): Wingspan $17.0 \mathrm{~mm}$. Head and thorax covered with white black-tipped scales, labial palpus white, segment 2 with black base and rare brown scales on outer surface, brush of scales underside, segment 3 acute, white mottled with black. Scape brown, flagellum white with brown rings, underside pubescent in male. Tegulae blackish-grey. Forewing covered by weakly raised, black-tipped scales, diffuse white spots on $1 / 4$ and $1 / 2$ of costal margin, subcostal vein with black interrupted streak from base to $1 / 2$ length, distinct black pattern around fold and in mid width from $2 / 3$ towards apex, white patch mottled in with brown from $1 / 5$ of dorsal margin to termen, cilia white, black-tipped. Hindwing and cilia grey.

Male genitalia. Unknown.

Female genitalia (Fig. 30): Sternum VIII about as longer as broad, weakly narrowed distally, membranous, densely covered with fine microtrichia, anterior margin with triangular medial sclerites; ostium sub-ovate, weakly broadened posteriorly, anterior margin strongly edged, with two transverse sclerotized belts; apophysis anterioris about as long as a length of segment VIII; antrum broad, as long as apophysis anterioris, narrowed in distal part towards very short, entirely sclerotized ductus bursae that bears numerous teeth before entrance to corpus bursae; corpus bursae sub-ovate, weakly broadened anteriorly; signum with well serrated arms, the anterior one slightly longer than the posterior.

Etymology. The species is named after Punda Milia in Kruger National Park, the type locality of the new species.

Distribution. RSA.

Biology. The holotype has been collected in early December.

\section{Tricerophora rukinga sp. $\mathrm{n}$.}

http://zoobank.org/D524CC4E-C3DC-4B74-A530-70C39B4EF1CC

Type material. Holotype $\widehat{\partial}$, "KENYA: Coast, Rukinga Estate $500 \mathrm{~m}, \mathrm{~S} \mathrm{3}{ }^{\circ} 42^{\prime} 22^{\prime}$ " E 38 46’34”, 14.xi.2012, Agassiz, Beavan \& Heckford" | "gen. slide 324/14 (=1542 DJLA), O. Bidzilya“" (DA). Paratypes. 1 ô, 1 , 

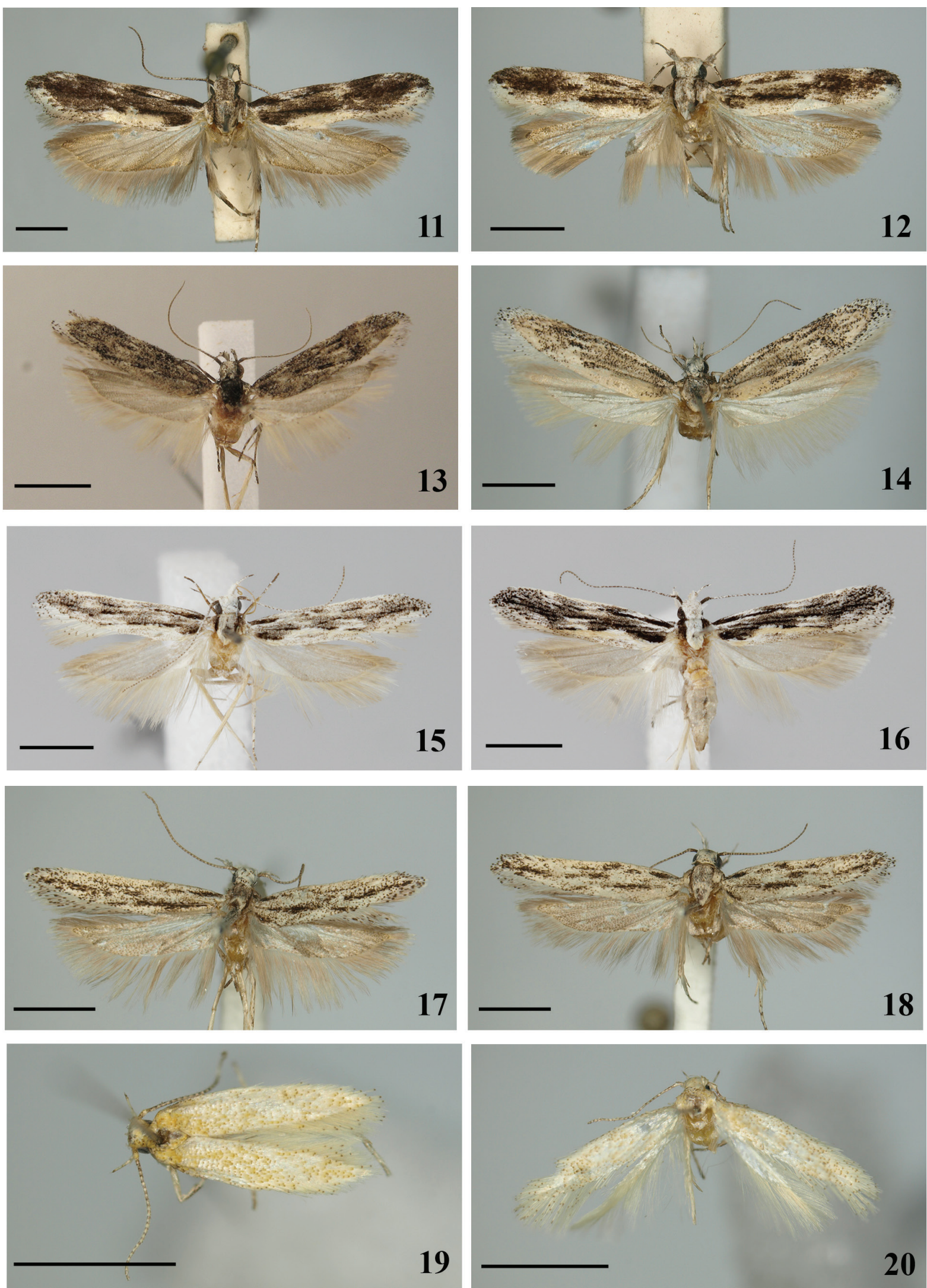

Figures 11-20. Adult of Tricerophora spp. 11. T. pundamilia sp. n., HT,, , Punda Milia (gen. slide 61/15, O. Bidzilya). 12. T. sp. A, đ̂, Wylies Poort (gen. slide 331/14, O. Bidzilya). 13-14. T. brumale sp. n. 13. HT, đ̂, Xaragu Camp (gen. slide 106/12, O. Bidzi-

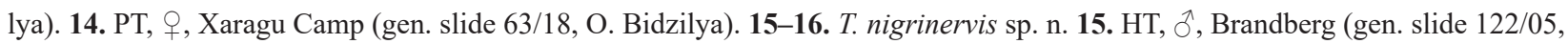
O. Bidzilya). 16. PT, $q$, Richtersveld (gen. slide 61/18, O. Bidzilya). 17-18. T. acutivalva sp. n. 17. HT, đ̃, Imam Sade (gen. slide 47/18, O. Bidzilya). 18. PT, đ̃, Imam Sade (gen. slide 1/18, O. Bidzilya). 19-20. T. minimorum sp. n. 19. HT, ô, Opuwo (gen. slide 361/14, O. Bidzilya). 20. PT, , , Varianto (gen. slide 536/14, O. Bidzilya). Scale bar $=2 \mathrm{~mm}$ 


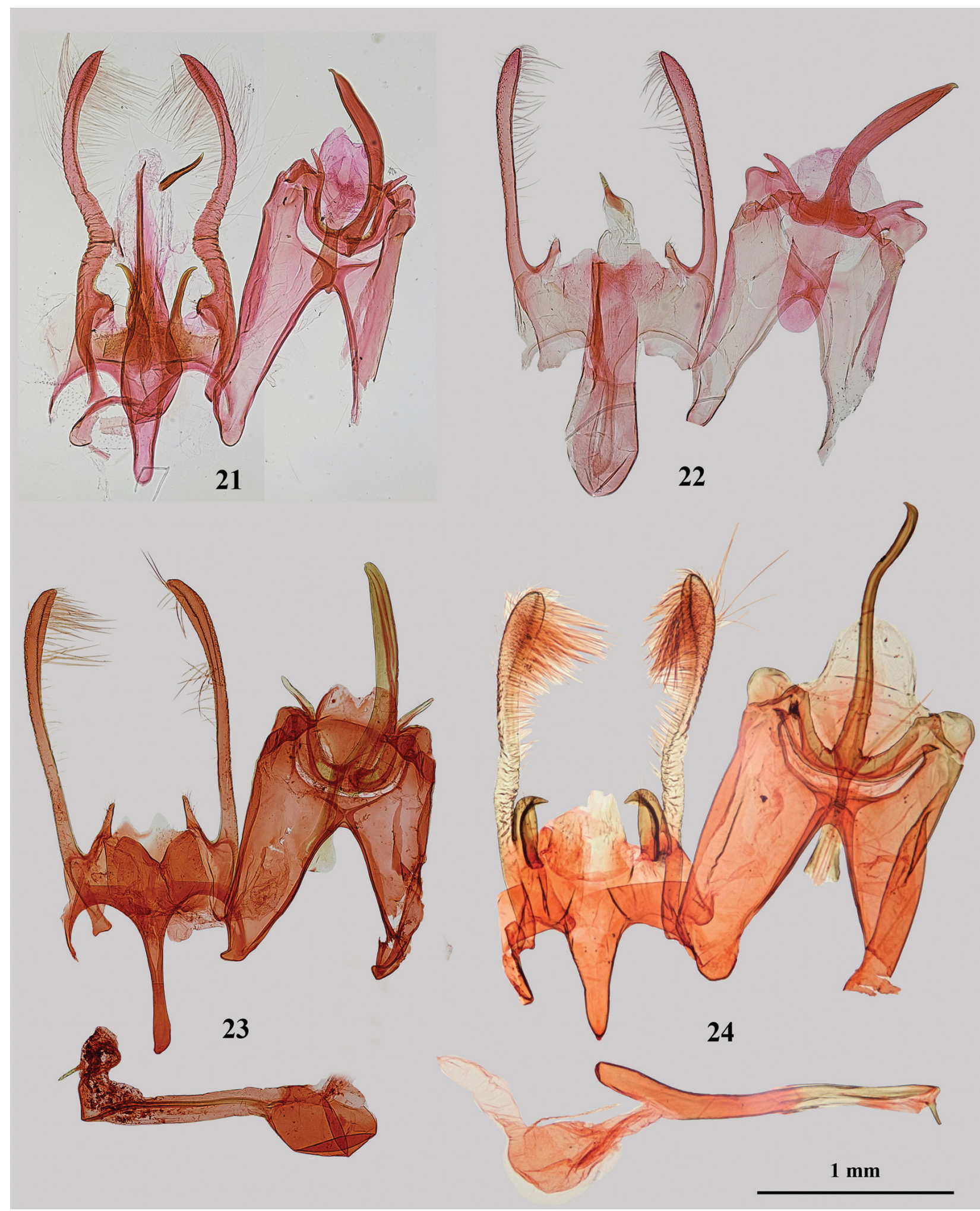

Figures 21-24. Male genitalia of Tricerophora spp. 21. T. commaculata, Zimbabwe (gen. slide 322/07, O. Bidzilya). 22. T. nigribasis, Brandberg (gen. slide 117/05, O. Bidzilya). 23. T. sp., Wylies Poort (gen. slide 331/14, O. Bidzilya). 24. T. rukinga sp. n., HT, Rukinga (gen. slide 324/14, O. Bidzilya (= 1542, DJLA)).

same data as for holotype; 1 , , same data as for holotype but 11.xi.2012 (Agassiz, Beavan \& Heckford) (gen. slide 325/14 (=1543), O. Bidzilya); 1 +, KENYA: Coast,

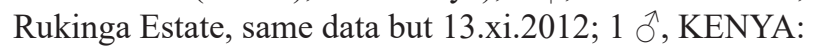

Coast, Rukinga Reserve, 520m, 3³5’15.7S, 3844’29.6E, 21.xi.2010 (Agassiz \& Ngugi); 1 +, KENYA: Coast,

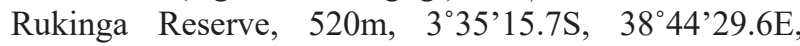
23.xi.2010 (Agassiz \& Ngugi) (all DA). 
Diagnosis. The new species is characterized externally by predominately black forewing with white pattern along dorsal margin and white blocks on $1 / 3$ and $2 / 3$ of costal margin. It can hardly be distinguished from $T$. pundamilia sp. $\mathrm{n}$. and T. commaculata without examination of the genitalia. The male genitalia are very characteristic having a long uncus sub-equal in length with tegumen, a stout sacculus broader than valva and with a pointed, inwardly curved apex as well as the phallus is extremely slender. The rounded, strongly edged ostium with one transverse medial belt, the broad and short antrum, the entirely sclerotized, very short ductus bursae and segment VIII with broad strongly sclerotized anterior margin are characteristic for the female genitalia.

Description. Adult (Figs 7-8): Wingspan 13.2 (ठ̋)14.0 (q) $\mathrm{mm}$. Head and thorax covered with white brown-tipped ( $q$ ) or grey brown-tipped ( $\delta$ ) scales, labial palpus white, segment 2 with black base and rare brown scales on outer surface, brush of scales underside, segment 3 acute, white mottled with black. Scape brown, flagellum white with brown belts, pubescent on underside in male. Tegulae blackish-grey ( $\left.)^{\top}\right)$ or creambrown $(+)$. Forewing covered with weakly raised blacktipped scales, diffuse white spots on $1 / 4$ and $1 / 2$ of costal margin, subcostal vein with black interrupted streak from base to $1 / 2$ length, distinct black pattern around fold and in mid width from $2 / 3$ towards to apex, white patch mottled with brown from base to termen along dorsal margin, cilia white, black-tipped. Hindwing and cilia grey.

Male genitalia (Fig. 24): Posterolateral processes of tegumen reduced; uncus very long, narrow; gnathos about two times shorter than uncus, sub-triangular, broadened from base towards trifid apex; tegumen twice as long as broad; valva moderately broad, wrinkled in basal half, distinctly broadened and densely haired in distal $1 / 3$, apex rounded, extending to 2/3 length of uncus; sacculus stout, broader than valva on base, about 1/4-1/5 length of valva, with inwardly curved tip; vinculum two times as broad as long, about 1/3 length of valva, posteromedial lobe irregular, extending to about $1 / 4-1 / 5$ length of the valva; saccus comparatively short, sub-triangular, gradually narrowed towards slightly pointed apex; phallus very slender, of even width, cornutus short, pointed.

Female genitalia (Fig. 31): Sternum VIII nearly as long as broad, weakly sclerotized, densely covered with fine microtrichia, anterior margin broadly sclerotized; ostium rounded, strongly edged posteriorly, with transverse medial belt; apophysis anterioris about as long as a length of segment VIII; antrum broad, half the length of apophysis anterioris, ductus bursae as long as antrum but narrower, entirely sclerotized; corpus bursae sub-ovate; signum with well serrated arms, the anterior one slightly longer than the posterior one.

Etymology. The species is named after the Rukinga Estate in Kenya, the type locality of the new species.

Distribution. Kenya.

Biology. Adults have been collected in November.
Tricerophora objecta (Meyrick, 1921), comb. n.

Telphusa objecta Meyrick, 1921 - Annals of the Transvaal Museum 8 (2): 70

Type material examined. Holotype of T. objecta, $\overbrace{\text { : }}$ [Zimbabwe] "Salisbury, Rhod., 30.12.'17, A.J.T. Janse" | "Telphusa objecta M., TYPE No: 662." | "g. 5546" (TMSA)

Other material examined. 1 , , [D.R. Congo] Katanya, Tshinkolobwe, 22.viii.1931 (Romieux) (gen. slide 103/18, O. Bidzilya) (MHNG)

Diagnosis. The species is recognizable externally by the paired white triangular spot in the middle of the costal and dorsal margin of the forewing. The female genitalia are very characteristic having broad, extremely anteriorly prolonged sternum VIII with a large, medial membranous window.

Description. Adult (Figs 9-10): Wingspan $18.0 \mathrm{~mm}$. Head and thorax white, segment 2 of labial palpus white with several brown-tipped scales on outer surface, base black, brush of raised scales underside, segment 3 white mixed with brown, slender, acute. Scape brown mottled with white underside, flagellum light brown with narrow white rings. Tegulae white with brown base. Forewing brown, rarely mottled with slightly raised black-tipped scales, white triangular spot in middle of costal margin and on the opposite side in middle of dorsal margin, another white smaller spot on $3 / 4$ of costa, cilia white browntipped; hindwing and cilia grey.

Male: Unknown.

Female genitalia (Fig. 32): Sternum VIII about as broad as long, evenly sclerotized in middle, weakly narrowed posteriorly, strongly sclerotized along lateral margins, anterior margin strongly projecting anteriorly forming a stout sub-rectangular lobe with large medial membranous rounded window with uneven edges; apophysis anterioris 3/4 length of segment VIII; antrum very long, tubular, with 15 transverse rings; ductus bursae slightly longer than anterior lobe of sternum VIII, with short sclerotized portion before entrance of corpus bursae, antrum weakly sclerotized, about half the length of ductus bursae, ductus bursae hidden under anterior lobe of sternum VIII but translucent and visible; corpus bursae prolonged; signum with long and broad, serrated arms of equal length.

Distribution. Zimbabwe, D.R. Congo.

Biology. Adults has been collected in December in Zimbabwe and in August in D.R. Congo.

Notes. Telphusa objecta was described from the single female holotype collected in Salisbury (Harare), Zimbabwe. Janse (1960: 58) noted that generic position of this species is uncertain and its assignment to Telphusa only provisional. The female genitalia of $T$. objecta share with species of Tricerophora laterally sclerotized sternum VIII, the long antrum and a signum with long serrated lobes. Despite unknown males, we have no doubt that the species belongs to Tricerophora. The ostium with transverse rings indicates the affinity of T. objecta to T. commaculata, T. pundamilia sp. n. and T. rukinga sp. n. 


\section{Tricerophora brumale sp. n.}

http://zoobank.org/E160659A-05A6-4E68-A429-6D9073BA45FF

Type material. Holotype $\hat{\sigma}$, "Namibia/Namib, Damaralan, Xaragu Camp, 561 m, 7.viii.2007, GEO-WG84, $14^{\circ} 20^{\prime} 042^{\prime}$ E $/-20^{\circ} 24^{\prime} 441^{\prime \prime S}$, leg. Dr. C. Wieser, Kärtner Landesmusem" |"gen. slide 106/12, O. Bidzilya" (KLM). Paratypes: 1 , same data as holotype (gen. slide 63/18, O. Bidzilya) (KLM)

Diagnosis. The new species is defined externally by cream-white forewing gradually mottled with black and brown but without distinct black markings and patterns. T. nigrinervis sp. $\mathrm{n}$. differs in the snow-white head without brown scales, more prominent black marking along veins and white area along dorsal margin of the forewing. T. acutivalva differs in the less black-irrorated and narrowed after half length of the forewing. The long and broad saccus, triangular gnathos, comparatively broad valva and triangular cornutus separate $T$. wieseri $\mathrm{sp}$. $\mathrm{n}$. from the rest of Tricerophora-species. A short antrum in combination with a long ductus bursae, pear-shaped corpus bursae and signum with broad weakly serrated arms are characteristic for the female genitalia.

Description. Adult (Figs 13-14): Wingspan 10.8$11.2 \mathrm{~mm}$. Head, thorax and tegulae covered with white black-tipped scales, frons white, the female paratype with a head completely white. Labial palpus up-curved, far protruding over the head, segment 2 white with blacktipped scales, nearly white in middle with brush beneath, segment 3 narrow, pointed, white with a few black scales mainly in middle. Scape black, antennal segments white with black rings, male flagellum covered beneath with numerous short hairs (ciliated). Forewing cream-white, densely mixed with black, 2-3 diffuse black patches near the base and in cell, cilia white, black-tipped. Hindwing light grey.

Male genitalia (Fig. 25): Posterolateral processes of tegumen short, pointed; uncus long, straight; gnathos slightly shorter than uncus, sub-triangular, broadened from base towards apex; tegumen two times long as broad; valva moderately broad, curved inwards in distal $1 / 4$, haired, slightly extending beyond the top of uncus, apex pointed; sacculus about 1/3 length of valva, straight, apex rounded; vinculum tree times as broad as long and about $1 / 4$ length of valva, posteromedial lobe triangular, extending to about $1 / 3$ length of valva; saccus moderately broad, weakly constricted before apex; phallus weakly swollen on base, cornutus short, triangular.

Female genitalia (Fig. 36): Sternum VIII slightly longer than broad, membranous; ostium indistinct; apophysis anterioris about as long as a length of segment VIII; antrum tubular, 1/3 length of apophysis anterioris; ductus bursae entirely sclerotized, of even width, as long as apophysis anterioris, with distinct transition towards pear-shaped corpus bursae; signum with broad, weakly serrated arms, the anterior one slightly longer and broader than the posterior one.
Etymology. The specific name is derived from Latin "brumalis" -, winter-like, and alludes to the winter activity of the adult.

Distribution. Namibia.

Biology. Adults have been collected in early August.

\section{Tricerophora nigrinervis sp. $\mathbf{n}$.}

http://zoobank.org/1C6EC60C-4200-4A96-A9D3-C332F200332B

Tricerophora sp. 2 - Bidzilya 2007: 99, figs 31, 35; pl. 7, fig. 3

Type material. Holotype $\curvearrowright$, "Namibia, Brandberg, 1100 m, 1.xii.2000, LF, W. Mey | "gen. slide 122/05, O. Bidzilya" (MfN). Paratypes: 1 + , same data as holotype (gen. slide 77/18, O. Bidzilya); 2 , same data, but $800 \mathrm{~m}$, 3.xii.2000 (Mey) (gen. slide 100/05, O. Bidzilya); 1 , same data, but 1400 m, 2.xii.2000 (Mey); 1 ふ, Namibia, Brandberg, Ugab, 30.xi.2000, LF (Mey); 1 \%, Namibia, Windhoek, Farm Ondekaremba, 18.ii.2008, Turm (Mey) (all MfN); 1 , Namibia/Namib, Damaralan, Xaragu Camp, 561 m, 7.viii.2007, GEO-WG84, 1420042 E/-20 24441 S, leg. Dr. C. Wieser, Kärtner Landesmusem (gen. slide 130/12, O. Bidzilya) (KLM); 1 9, RSA, Richtersveld, Numees, Helskloof Gate, 9-12.x.2001, LF (Mey) (gen. slide 61/18, O. Bidzilya) (MfN)

Diagnosis. The new species can be recognized by its relatively small wingspan, snow-white head and thorax and contrast blackish-white forewing distinctly mottled with black mainly along veins and fold. T. brumale sp. $\mathrm{n}$. and T. acutivalva sp. n. differ in more extensive black irroration on the head, thorax and forewing and less distinct (by T. brumale sp. n.) black pattern along veins. The long phallus with two cornuti in combination with long posteromedial lobe of vinculum and comparatively short and broad gnathos are characteristic for the male genitalia. The female genitalia are defined by the long ductus bursae with sclerotized serrated folds, corpus bursae with posterolateral accessory bursa and short arms of the signum.

Description. Adult (Figs 15-16): Wingspan 11.1$11.8 \mathrm{~mm}$. Head and thorax white, labial palpus white, segment 2 with black base and rare brown scales on outer surface, brush of scales underside, segment 3 acute, white mottled with black. Scape brown, flagellum white with brown belts, pubescent by male on underside. Tegulae black. Forewing covered with white, black-tipped scales, diffuse white spots on $1 / 2$ and $3 / 4$ of costal margin, subcostal vein black from base to $1 / 2$ length, black streaks along veins in costal half and in fold, whitish-cream patch mottled with brown in middle from base to nearly $1 / 2-2 / 3$ of dorsal margin, diffuse white tornal spot on $3 / 4$, cilia white, black-tipped. Hindwing and cilia grey.

Male genitalia (Fig. 27): Posterolateral processes of tegumen short, pointed; uncus long, evenly curved; gnathos half the length of uncus, broad, about of even width, top rounded; tegumen twice as long as broad; val- 


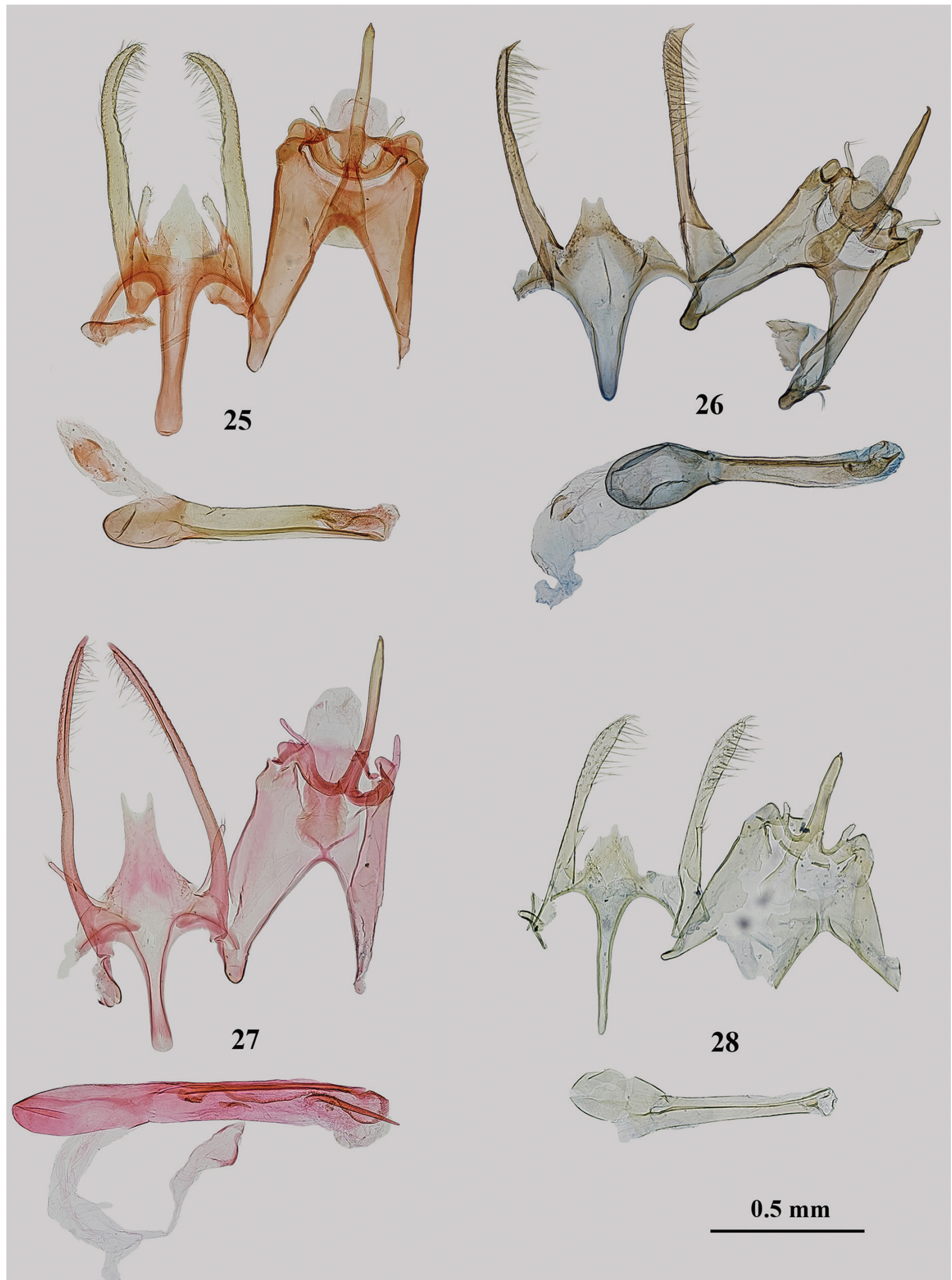

Figures 25-28. Male genitalia of Tricerophora spp. 25. T. brumale sp. n., HT, Xaragu Camp (gen. slide 106/12, O. Bidzilya). 26. T. acutivalva sp. n., HT, Imam Sade (gen. slide 47/18, O. Bidzilya). 27. T. nigrinervis sp. n., HT, Brandberg (gen. slide 122/05, O. Bidzilya). 28. T. minimorum sp. n., HT, Opuwo (gen. slide 361/14, O. Bidzilya). 


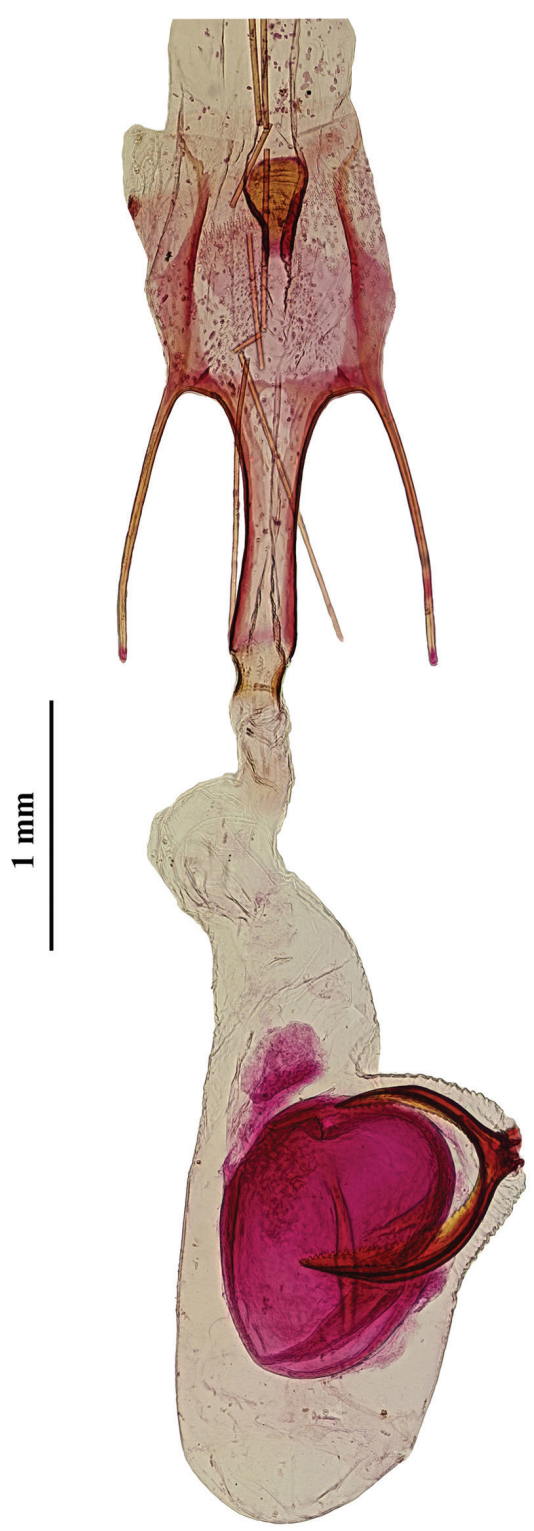

29

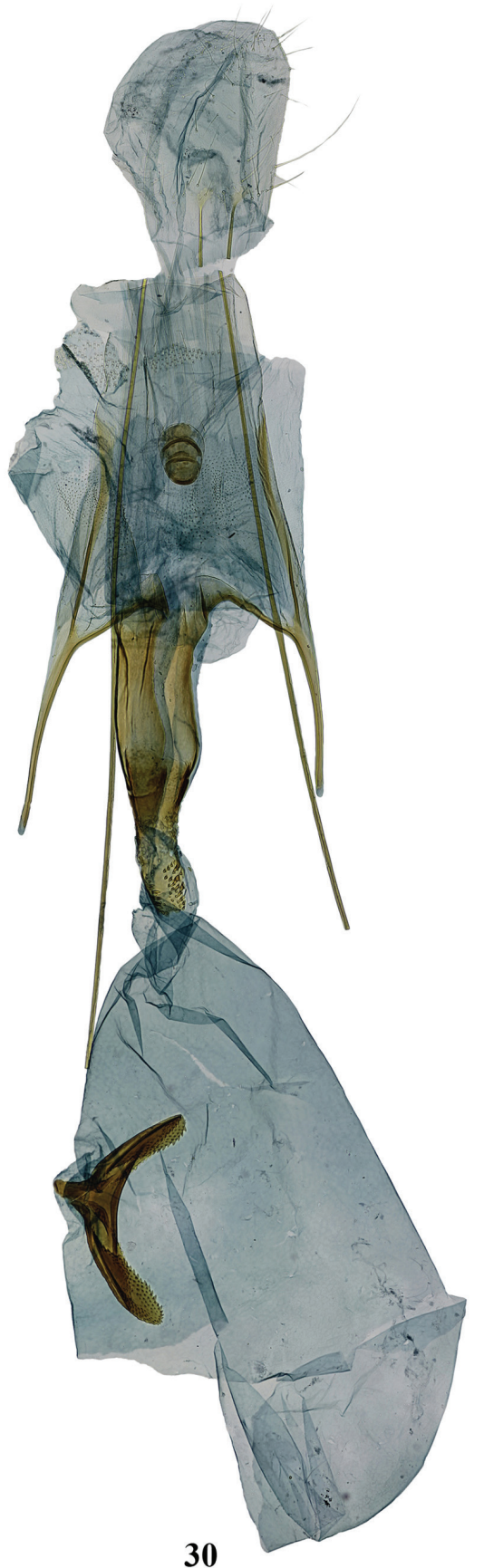

30

Figures 29-30. Female genitalia of Tricerophora spp. 29. T. commaculata, HT, Magude (gen. slide 5544). 30. T. pundamilia sp. n., Punda Milia, HT (gen. slide 61/15, O. Bidzilya).

va nearly straight, narrow, of even width, rarely haired, slightly extending beyond tip of uncus, apex pointed; sacculus about 1/3-1/4 length of valva, very narrow; vinculum three times as broad as long, about 1/6-1/7 length of valva, posteromedial lobe long, extending nearly to half length of the valva, medially with triangular emargination; saccus moderately broad, sligthly narrowed in middle, apex rounded; phallus nearly of even width, as long as tegumen and uncus, medial cornutus short, apical cornutus long and slender, weakly curved at base, than straight, pointed.
Female genitalia (Fig. 35): Segment VIII about as long as broad, sternum VIII membranous, ostium indistinct; apophysis anterioris slightly longer than segment VIII; antrum funnel-shaped, gradually narrowed anteriorly, longer than apophysis anterioris, constricted in the place of connection to ductus bursae; ductus bursae broader and slightly shorter than antrum, with several strongly serrated folds projecting into the corpus bursae; corpus bursae rounded, with broad, partially sclerotized posterior-lateral accessory bursa; signum with very short anterior and posterior arms and broad medial ridge. 

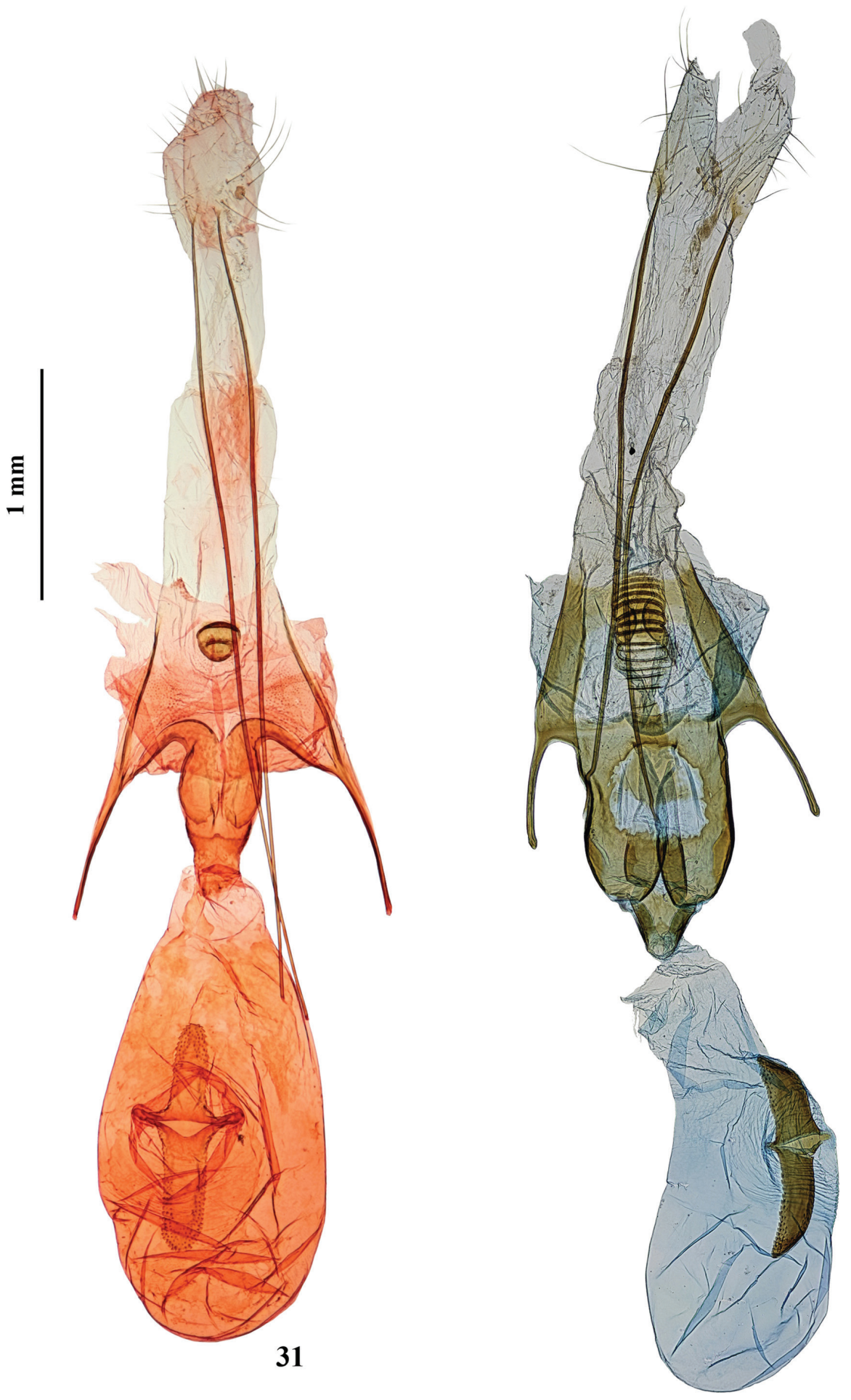

32

Figures 31-32. Female genitalia of Tricerophora spp. 31. T. rukinga sp. n., PT, Rukinga (gen. slide 325/14, O. Bidzilya (= 1543, DJLA)). 32. T. objecta, Kenya, Tschinkolobwe (gen. slide 103/18, O. Bidzilya).

Etymology. The specific name is derived from Latin "niger" - black and "nervus" - vein, reflecting the characteristic forewing pattern of the new species.

Distribution. Namibia, RSA.

Biology. Adults have been collected in August, October, December and February up to $1100 \mathrm{~m}$ elevation at the Brandberg (Namibia).

\section{Tricerophora acutivalva sp. $\mathrm{n}$.}

http://zoobank.org/C10FB999-029D-4FCD-8711-4D73DA3B04B9

Type material. Holotype đ̄, [Iran], "S-Iran, Strasse Shiraz-Kazerun, Imam Sade, 1200 m, 3.vi.1969, H.G. Amsel leg." | "gen. slide 47/18, O. Bidzilya" (SMNK); Paratypes: $3 \hat{\jmath}, 4$ ㅇ, same data as holotype (gen. slide 1/18 $\hat{\circ}$, 


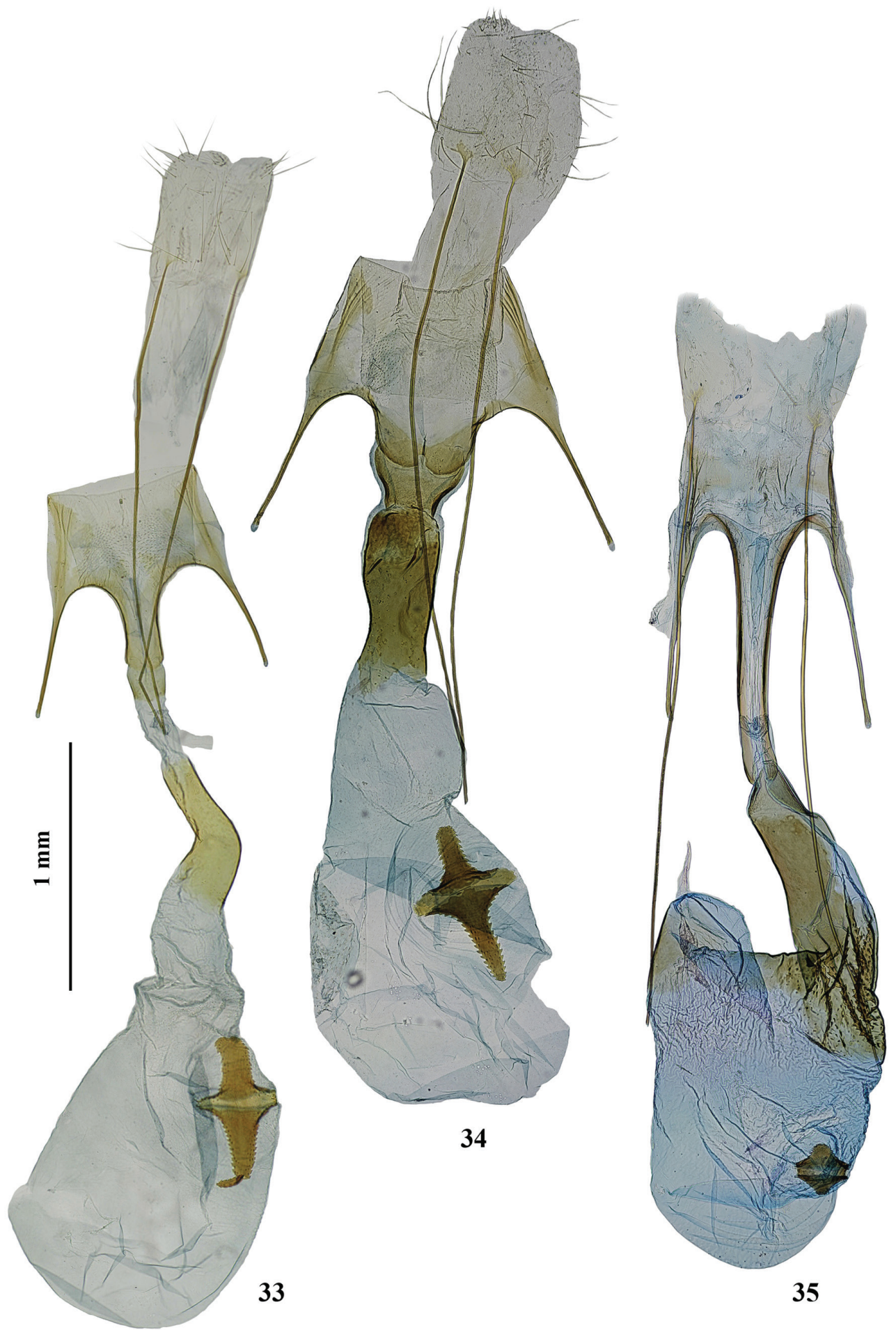

Figures 33-35. Female genitalia of Tricerophora spp. 33. T. nigribasis, PT, Abachaus (gen. slide 600/14, O. Bidzilya). 34. T. sp., Brandberg (gen. slide 105/05, O. Bidzilya). 35. T. nigrinervis sp. n., PT, Brandberg (gen. slide 77/18, O. Bidzilya).

77/18 9 , O. Bidzilya); 1 ふૈ, S-Iran, 4-7.vi.1969, Miyan Katal, 1900 m, östl. Kazerun, 5140’öL, 29³0'nB (Amsel) (all SMNK)

Diagnosis. The new species is defined externally by the forewing narrowed in distal half and less extensive black pattern contrary to the other blackish-white Tricerophora-species. T. brumale sp. n. is more strong- ly black-irrorated and the forewings are not narrowed in distal half. The apically acute valva with merged sacculus and broad sub-triangular saccus are characteristic for the male genitalia. The female genitalia are distinct by sternum VIII broadly sclerotized laterally in combination with long and broad ductus bursae which is sclerotized in distal half only. 

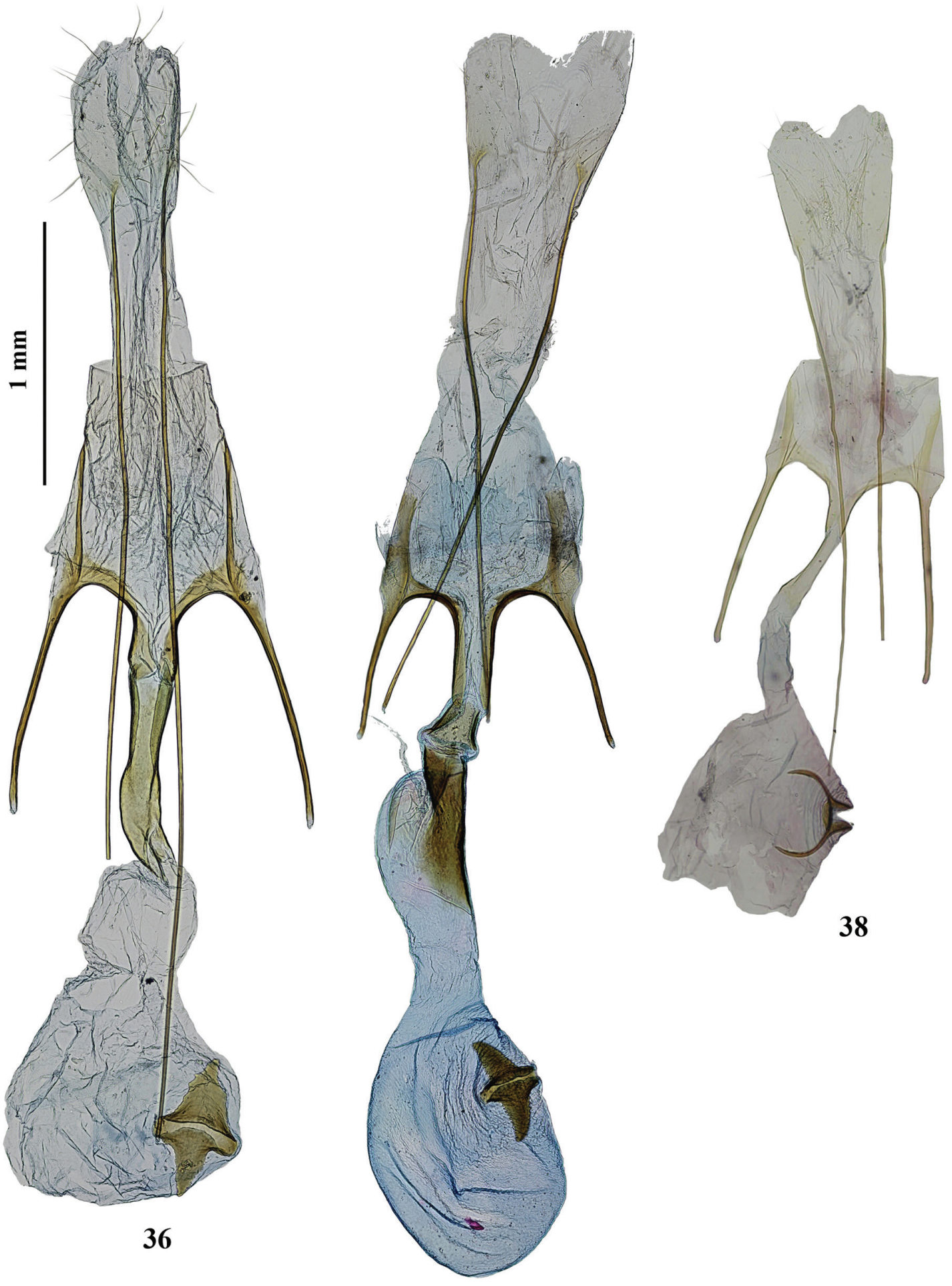

38

Figures 36-38. Female genitalia of Tricerophora spp. 36. T. brumale sp. n., PT, Xaragu Camp (gen. slide 63/18, O. Bidzilya). 37. T. acutivalva sp. n., PT, Imam Sade (gen. slide 77/18, O. Bidzilya). 38. T. minimorum sp. n, PT, Varianto (gen. slide 536/14, O. Bidzilya).

Description. Adult (Figs 17-18): Wingspan 10.0-12.0 $\mathrm{mm}$. Head white with rare black-tipped scales on neck, labial palpus white, segment 2 with black base and rare black scales on outer surface, brush of scales underside, segment 3 acute, white mottled. Scape light brown, flagellum light brown with white belts, pubescent by male on underside. Thorax and tegulae white mixed with black-tipped scales. Forewing white with veins distinctly mottled with black, black streak on mid width from $2 / 3$ length towards apex, cilia white black-tipped. Hindwing and cilia grey. 
Male genitalia (Fig. 26): Posterolateral processes of tegumen moderately long, pointed; uncus straight; gnathos about 3/4 length of uncus, weakly constricted in middle, apex broadly rounded; tegumen twice as long as broad; valva moderately broad, of even width, haired, far extending beyond the top of uncus, apex elongated and distinctly pointed; sacculus merged with valva; vinculum four times as broad as long, about 1/6 length of valva, posteromedial lobe trapezoidal, medially broadly emarginated, extending to 1/4 length of valva; saccus broad, sub-triangular, apex rounded; phallus swollen on base, slightly broadened distally, cornutus short, broad on base.

Female genitalia (Fig. 37): Sternum VIII as long as broad, membranous except for strongly sclerotized areas along lateral margins; ostium indistinct; apophysis anterioris slightly longer than segment VIII; antrum tubular, somewhat broadened in distal 3/4, as long as length of apophysis anterioris; ductus bursae 1.5 times as broad as antrum, with sclerotized patch in distal half along right margin, left margin weakly inflated distally, twice as long as apophysis anterioris, with distinct transition towards eggshaped corpus bursae; arms of signum of equal length and width, gradually narrowed apically, distinctly serrated.

Etymology. The specific name is derived from Latin "acutus" - sharp, and "valva" - clasper, referring the apically pointed valva of the new species.

Distribution. Iran.

Biology. Adults have been collected in early June.

\section{Tricerophora minimorum sp. $\mathbf{n}$.}

http://zoobank.org/BA95D532-3209-46D3-8C7C-5274C561D6D9

Type material. Holotype $\widehat{\partial}$, "Namibia, Opuwo, Op. County Hotel, 2.ix.2012, 1237 m, W. Mey“ | "gen. slide 361/14, O. Bidzilya“ (MfN). Paratypes: 1 ㅇ, Namibia, Varianto Farm, Otavi Mountains, 29-31.iii.2003 (Mey) (gen. slide 576/14, O. Bidzilya) (MfN)

Diagnosis. The species is unmistakable separated from rest of Tricerophora species by its exceptionally small size and uniformly coloured yellowish-white forewing. The male genitalia are defined by the saccus that is about as long as the length of valva, the uncus that is as long as gnathos and a very short cornutus in the phallus. T. pundamilia sp. $\mathrm{n}$. is somewhat similar but the saccus is about half the length of valva. The long apophysis anterioris and ductus bursae equally divided in sclerotized and membranous halves are characteristic for the female genitalia.

Description. Adult (Figs 19-20): Wingspan $7.0 \mathrm{~mm}$. Head and labial palpus yellowish-white, segment 3 mixed with brown on base and before apex. Scape yellow mottled with light brown, flagellum yellow with broad brown rings, pubescent by male on underside. Thorax, tegulae and forewing covered with yellowish-white brown-tipped scales, cilia white. Hindwing and cilia light grey.

Male genitalia (Fig. 28): Posterolateral processes of tegumen short, pointed; uncus straight; gnathos as long as uncus, narrow with distinctly broadened round apex; teg- umen 1.5 times as long as broad; valva narrow, straight, weakly broadened and haired dorsally, slightly extending beyond the tip of uncus, apex pointed; sacculus about $1 / 3$ length of valva, very narrow, straight; vinculum 3.5-4 times as broad as long, about $1 / 4-1 / 5$ times length of valva, posteromedial lobe sub-triangular, extending to $1 / 3$ length of valva; saccus long and narrow, apex rounded; phallus slightly swollen at base, cornutus short.

Female genitalia (Fig. 38): Sternum VIII slightly broader than long, evenly sclerotized, ostium indistinct; apophysis anterioris twice as long as segment VIII; antrum narrow, funnel-shaped, 1/3 length of apophysis anterioris; ductus bursae as long as apophysis anterioris, weakly broadened towards corpus bursae, sclerotized in proximal half; corpus bursae rounded; signum with long, serrated arms of equal length.

Etymology. The specific name refers to the small size of the new species.

Distribution. Namibia.

Biology. Adults have been collected in September and March.

\section{Acknowledgements}

We are thankful to Martin Krüger (TMSA), David Agassiz (NHM London, UK), Christian Wieser (KLM) and Bernard Landry (MHNG) for providing access to the collection under their care and for sending additional information on specimens.

The visits of the first author to MfN and TMSA were financially supported by the German Academic Exchange Service (DAAD) and Ernst Mayr Travel Grant from the Museum of Comparative Zoology, Harvard University (USA). Field work in Namibia by the second author was funded by the MfN, DFG and the BIOTA Project (BMBF).

We are thankful to the editor of DEZ and two reviewers, who made constructive suggestions to improve the manuscript. Authors acknowledge the MfN for waiving the authors fees and David Agassiz for the linguistic correction of the manuscript.

\section{References}

Bidzilya O (2007) Gelechiidae (Lepidoptera: Gelechioidea). In: Mey W (Ed.) The Lepidoptera of the Brandberg Massif in Namibia. Part 2. Esperiana Memoir 4: 91-118. [pl. 5-8]

Bidzilya O, Li H (2010) Review of the genus Agnippe (Lepidoptera: Gelechioidea) in the Palaearctic region. European Journal of Entomology 107: 247-265. https://doi.org/10.14411/eje.2010.033

Huemer P (1988) A taxonomic revision of Caryocolum (Lepidoptera, Gelechiidae). Bulletin of the British Museum (Natural History), Entomology 57(3): 439-571.

Huemer P, Karsholt O (1999) Gelechiidae I (Gelechiidae: Gelechiinae, Teleiodinae). In: Huemer P, Karsholt O, Lyneborg L (Eds) Microlepidoptera of Europe. Vol. 3. Apollo Books, Stenstrup, 356 pp 
Janse AJT (1958) Gelechiidae. The Moths of South Africa 6(1): 1-144. [pl. 1-32]

Janse AJT (1960) Gelechiidae. The Moths of South Africa 6(2): 145240. [pl. 33-129]

Karsholt O, Mutanen M, Lee S, Kaila L (2013) A molecular analysis of the Gelechiidae (Lepidoptera, Gelechioidea) with an interpretative grouping of its taxa. Systematic Entomology 38: 334-348. https:// doi.org/10.1111/syen.12006
Kristensen NP [Ed.] (2003) Lepidoptera: Moths and Butterflies 2. Morphology, Physiology and Development. Handbook of Zoology 4(36). Berlin \& New York, 564 pp.

Mey W (2011) Basic pattern of Lepidoptera diversity in southwestern Africa. Esperiana Memoir 6: 1-315.

Meyrick E (1921) Descriptions of South African Micro-Lepidoptera. Annals of the Transvaal Museum 8(2): 49-148.

Pitkin L (1986) A technique for the preparation of complex male genitalia in Microlepidoptera. Entomologist's Gazette 37: 173-179. 